\title{
Leis, Causas e Poderes
}

Laws, Causes and Powers

\author{
Luiz Henrique De ARAújo Dutra \\ UFSC, UnB, CNPq, BRASIL \\ lhdutra@cfh.ufsc.br
}

\begin{abstract}
This paper deals with the notions of scientific law, natural causes, and the powers of causes to produce their effects from the point of view of perspectival realism. In the first section I deal with the conception of cause defended by George H. Lewes, one of the forerunners of British emergentism, along with John Stuart Mill. In the next section I deal with the notion of heteropathic laws of Mill. In the last section I deploy these notions in my explanation of natural phenomena as emergent processes. I put emphasis on the fact that the base conditions of an emergent are not its causes.
\end{abstract}

Keywords: Laws $\bullet$ causes $\bullet$ powers $\bullet$ emergence $\bullet$ perspectivism $\bullet$ realism

\section{Introdução}

Neste artigo vamos procurar explicar e defender a concepção de leis científicas relativa ao emergestismo perspectivista. Vamos partir da noção de lei da natureza proposta por George Henry Lewes e da noção de lei heteropática de John Stuart Mill, embora suas concepções não coincidam a esse respeito. Lewes e Mill são precursores do emergentismo britânico do início do século XX e é a essa tradição que nosso emergentismo perspectivista se liga. A ideia fundamental - e que, por sinal, está mais claramente expressa em Mill do que em Lewes - é que a realidade vai se tornando cada vez mais complexa, de tal modo que nosso conhecimento daqueles processos e coisas que Lewes denominou emergentes (em oposição aos resultantes) não decorre dedutivamente de nosso conhecimento de suas condições de base ou, mais especificamente, daqueles fatores que, uma vez em conjunção, levam ao surgimento de realidades novas. Para ambos esses autores, o surgimento da vida e da mente humana são os melhores exemplos a esse respeito. Isso quer dizer que, tomando uma perspectiva evolucionista - essa, sim, muito mais claramente esposada por Lewes que por Mill —, as ciências da vida (que incluem todos os ramos da biologia, mas também a psicologia ou a ciência da mente) não são redutíveis à ciência dos eventos naturais brutos ou inorgânicos. E, logo, as leis biológicas e psicológicas são irredutíveis às leis da natureza que expressam relações entre realidades inorgânicas. 
Todavia, para a filosofia da ciência posterior, falar de leis biológicas e psicológicas se tornou algo não apenas temerário, questionável, mas impróprio mesmo. A ideia nem sempre defendida explicitamente, mas certamente pressuposta por muitas discussões contemporâneas, é que enquanto no domínio dos fenômenos físicos e químicos em geral podemos elaborar leis (algumas vezes se diz leis causais), no domínio dos fenômenos vitais e mentais não cabe fazer isso. Para utilizarmos uma expressão que se tornou famosa graças a Donald Davidson (mais especificamente em relação ao domínio do mental), o anomalismo dos eventos mentais ou, mais especificamente, seu caráter não nomológico os exclui de qualquer tentativa nossa de retratá-los por meio da elaboração de leis, ou pelo menos de leis causais genuínas, como diz esse autor. Mas então isso quer dizer que pode haver leis não causais ou não genuínas, e o próprio Davidson (1980) admite que podemos chegar a correlações entre os eventos mentais e expressá-las por meio de formulações legiformes ou nomológicas, que são apenas generalizações empíricas. Isso não implica, todavia, que determinados eventos mentais tenham o poder de causar outros eventos mentais.

A posição de Davidson é apenas uma entre muitas e as há também com relação especificamente ao caso dos eventos biológicos. Assim como no caso de Davidson, muitas vezes aparece mais cedo ou mais tarde a noção de que as leis científicas expressam relações causais e que aqueles eventos apontados por elas como causas possuem o poder de produzir aqueles eventos apontados como seus efeitos. Ora, um aspecto no qual o pensamento de Lewes é muito interessante é sua concepção da causalidade ou, mais especificamente, como veremos, sua ideia de que causas e efeitos são, na verdade, apenas visões diferentes que temos dos mesmos acontecimentos. Embora tanto Mill quanto Lewes estivessem profundamente influenciados pelo positivismo de Auguste Comte e, portanto, partissem da noção comtiana de que as leis expressam como os eventos acontecem e não suas causas propriamente, seus porquês (os poderes que permitiriam a determinadas realidades engendrar outras), Lewes é mais consistente que Mill na aplicação dessa noção e, inclusive, critica Mill a esse respeito.

Como sabemos, a discussão sobre causas e poderes remonta aos empiristas britânicos, especialmente Locke e Hume. Ora, nesses dois filósofos está clara a ideia de que nosso conhecimento não alcança quaisquer realidades ocultas que fariam a ligação entre as causas e os efeitos que podemos observar. A noção que perdurou e chegou ao pensamento de Kant é que se há tais realidades ocultas ou inacessíveis a nossas capacidades cognitivas, elas estão sempre ipso facto para além da experiência possível e, logo, pertencem ao que Kant denominou coisas-em-si. Nesse aspecto o pensamento de Lewes também é muito interessante, pois ele rejeita a ideia kantiana de coisa-em-si como um domínio inacessível ao conhecimento humano. É o reconhecimento do caráter perspectivista de seu realismo fundamentado (reasoned realism, como o próprio autor o chama) que permite percebermos a plausibilidade de sua 
posição e de sua crítica a Kant e a toda a tradição para a qual a relação entre causa e efeito é uma relação temporal, isto é, tal como ela está expressa claramente em Locke, Hume e Kant, uma relação que estabelecemos entre eventos que se sucedem no tempo.

Uma das vantagens da teoria da causalidade de Lewes, como veremos, é que ela permite resolver com facilidade um problema difícil para os demais autores citados, entre muitos outros, que é o problema da simultaneidade entre os fatores de determinados acontecimentos, fatores esses que parecem agir causalmente uns sobre os outros, mas que se dão ao mesmo tempo, não correspondendo, portanto, ao esquema da sucessão temporal que seria típica das relações causais. Para isso Kant elaborou a categoria de comunidade ou ação recíproca, distinguindo-a da categoria de causação, respectivamente a terceira e a segunda categorias de relação na tábua das categorias do entendimento puro.

A esse respeito os exemplos mais notórios vêm da astronomia e envolvem a noção de gravitação. Por exemplo, do ponto de vista da mecânica clássica, o que explica o movimento mutuamente relativo da terra e da lua é a atração gravitacional que esses corpos celestes exercem um sobre o outro. O problema aqui é justamente que as leis do movimento nesse e em outros casos expressam não somente como tais movimentos se dão, mas pressupõem uma espécie de poder oculto, a gravidade justamente, uma realidade sobre a qual o próprio Newton não queria levantar hipóteses, como se tornou bem conhecido na filosofia da ciência da natureza desde então. Sem evocar tal poder oculto, é como se o movimento da terra fosse causa daquele da lua e, por sua vez, esse efeito seria causa de sua causa. ${ }^{1}$

O realismo de Lewes é distinto do realismo sobre os poderes de todos esses autores citados acima e de seu realismo sobre capacidades como talvez seja preferível dizer hoje, seguindo Nancy Cartwright (1989). Lewes é também um realista sobre os poderes ou capacidades naturais (inclusive as vitais e as mentais), mas de uma forma perspectivista, como procuraremos mostrar. O realismo perspectivista que já defendemos em outros trabalhos, seguindo a ideia de perspectivismo de Ronald Giere (2006), permite reabilitar a própria noção de lei científica, embora esse último autor não pense assim. ${ }^{2}$ Como veremos, ao resgatarmos o perspectivismo de Lewes, poderemos voltar a falar de leis em quaisquer domínios do conhecimento da realidade, pois o perspectivismo permite afastar os compromissos metafísicos com os poderes ocultos das causas para engendrar seus efeitos. Mais especificamente, podemos mesmo eliminar o discurso causalista e mostrar que as condições de base de um emergente e esse último são simultâneas, e não que aquelas são causas do emergente; ou, utilizando a forma de expressão devida a Mill, as leis heteropáticas que descrevem o comportamento dos emergentes descrevem os mesmos acontecimentos que são descritos pelas leis relativas ao comportamento de suas condições de base. Por exemplo, determinadas leis que expressam as relações entre eventos mentais descre- 
vem a mesma região do mundo, o mesmo locus, digamos, os mesmos acontecimentos descritos pelas leis neurofisiológicas que expressam as relações entre estruturas neuronais. Essa é uma ideia claramente proposta por Lewes.

\section{As leis naturais segundo o realismo fundamentado de Lewes}

Seguir uma lei é seguir uma determinação ou vontade superior — essa é a significação do termo quando se trata de leis no sentido jurídico ou social, que é a significação original ou primeira do termo "lei". Portanto, apenas em um sentido metafórico, diríamos, os acontecimentos naturais podem seguir leis ou, mais precisamente, se desenrolarem segundo leis. A origem do emprego do termo "lei" no caso de eventos naturais é essa mesma e, numa visão teológica ou criacionista do mundo presume que o Criador imprimiu na natureza sua vontade, que o desenrolar dos acontecimentos naturais expressa a forma como Ele quer que as coisas se deem, já que, obviamente, as coisas não podem seguir as leis da natureza por si próprias. É claro que, segundo uma visão evolucionista do mundo, a metáfora é inadequada, pois pode conduzir a pensar que há um direcionamento dos processos naturais, que há causas finais na natureza, de forma semelhante ao direcionamento que o ser humano pode dar para suas ações propositais. Assim, no melhor dos casos, uma lei da natureza só pode expressar a forma como os acontecimentos se dão - e, portanto, só pode ter relação com nossa forma de descrevê-los. Essa é basicamente a postura original adotada por Lewes e por Mill, seguindo a ideia proposta por Comte. ${ }^{3}$

A preferência de Comte pelo termo "lei" em lugar de "causa" era justamente para afastar a concepção metafísica de que as causas são poderes empregados por determinadas agências para conduzir os acontecimentos. A preferência mais recente entre muitos autores pela expressão "lei científica" em lugar de "lei da natureza" expressa uma ideia semelhante, isto é, aquela de que podemos relatar as formas usuais segundo as quais os acontecimentos se dão, formas que podem ser mesmo invariantes, mas que isso não implica nenhuma agência ou qualquer poder oculto por essa última controlado. É nessa mesma direção que vão as reflexões de Lewes. Ele diz, por exemplo:

A concepção empírica de Lei é a de uma abstração de dependências observáveis. É, assim, outro termo para Causa, outro aspecto de um Fato. É um termo para Causa quando expressa o processo e as condições de uma mudança, - p. ex., a lei da Gravitação. É um termo para Fato quando expressa essas condições apenas, sem referência à mudança, — p. ex., o fato da Gravitação, o fato de que o ar possui peso, de que a pressão em um fluido se propaga igualmente em todas as direções. Uma vez que os fatos e as causas 
são inumeráveis, e que são de diversos graus de importância e frequência, é útil ter um termo que designe esses fatos ou causas que possuem uma especial importância; o termo escolhido foi Lei.

$[\ldots]$

Uma Lei da Natureza não é um Agente nem uma Agência por meio da qual as substâncias são controladas, mas uma expressão abstrata de uma série de posições que as substâncias assumem sob determinadas condições. Não se trata de um criador dos fenômenos; é a fórmula deles. Não os precede ou conduz; evolui por meio deles. (Lewes 1875a, pp.335-6.)

Essa concepção de lei da natureza defendida por Lewes só é bem compreendida, contudo, dadas suas concepções de causa e de abstração. E essas noções estão intimamente relacionadas com sua concepção de ciência. O autor diz a esse respeito:

Pois nada é mais claramente demonstrável que o seguinte: aquilo que é chamado de Ciência exata é também uma construção puramente ideal, lidando basicamente com abstrações e não com realidades concretas, de tal forma que a objeção válida contra qualquer sistema de Metafísica não é que ele se mova em um mundo de concepções ideais, mas que suas concepções foram construídas de maneira ilegítima ou aplicadas de maneira ilógica. (Lewes 1875a, p.58.)

Segundo Lewes, o conhecimento que provém dessa ciência da natureza é o conhecimento das relações entre as coisas, pois essas últimas são suas relações (Lewes 1875a, p.59). E por isso mesmo, como já mencionamos, não cabe perguntar pela relação do que é conhecido com o que não pode ser conhecido (a coisa-em-si kantiana). Desse modo, o papel das leis é fundamental na ciência, pois elas expressam tais relações entre as coisas. ${ }^{4} \mathrm{O}$ objetivo da ciência, segundo o autor, é "detectar a ordem geral das Coisas, como é manifesta em grupos particulares de fenômenos, isto é, as leis abstratas do Ser sob condições particulares" (Lewes 1875a, p.60). Assim sendo, o problema da metafísica em comparação com a ciência empírica não está no fato de abstrair de condições concretas, mas de fazer isso de maneira inadequada. As leis que a ciência vai elaborar não estão nos próprios fenômenos, tal como um realismo ingênuo poderia supor, isto é, elas não são fatos gerais que determinariam fatos particulares. A generalidade inerente às leis científicas está em nós, diz Lewes. Ele comenta então: ${ }^{5}$

Mas tão logo passamos da observação das mudanças para a concepção de sua Lei, a distinção entre Concepção e Lei começa a se desfazer: reconhecemos que a Lei não está nos fatos mas em nossas mentes; se as tirássemos dos fatos, nós as construiríamos de novo e as colocaríamos no lugar dos fatos. Se essa construção deve ser encarada como uma Lei objetiva ou como uma Concepção subjetiva, isso depende do ponto de vista; é ambas as coisas ou qualquer uma delas. (Lewes 1875a, p.70.) 
Aqui começamos a ver o perspectivismo de Lewes, segundo o qual uma coisa e seu conceito são o mesmo, apenas ora encarado objetivamente, ora encarado subjetivamente. E, segundo ele, tanto uma concepção quanto uma percepção são construções lógicas (Lewes 1875a, p.71). De acordo com esse perspectivismo, que é uma forma de realismo - o realismo fundamentado de Lewes —, isso não torna a ciência menos objetiva. Lewes diz:

Se as Leis fossem simplesmente nossas Concepções - e elas são as Notações do que a Experiência revelou ser a Ordem na qual os fenômenos coexistem e se sucedem uns aos outros - , é claro que esse Idealismo requereria uma base no Realismo, e que nossas Concepções sejam válidas quando encaradas objetivamente como Leis, isso deve ser capaz de redução a uma origem sensível, sendo que cada um dos seus elementos constitutivos deve ser uma experiência real e a ordem de sua combinação deve ser real. (Lewes 1875a, p.71.)

A ideia de Lewes de que qualquer realidade pode ser encarada ora objetiva, ora subjetivamente, se aplica também, é claro, ao caso das realidades vitais e mentais, nesse último caso, antecipando uma posição na filosofia da mente muito semelhante àquela de Davidson. Segundo Lewes (1875a, p.103s), não cabe perguntarmos se um evento mental tem como causa um evento físico (ou neurofisiológico), pois isso seria o mesmo que perguntar se o lado côncavo de uma superfície curva é a causa de seu lado convexo, ou vice versa. Todo evento mental possui um correspondente neurológico; a referência ao primeiro significa tomá-lo subjetivamente, e ao segundo, objetivamente. Como nossos conceitos são estados de consciência, não podemos distinguilos dos processos físicos e neurofisiológicos correlatos, tomando esses últimos como causas dos primeiros. Trata-se, portanto, de uma doutrina elaborada que permite a unidade entre as ciências naturais, entre elas as ciências da vida, e as ciências do espírito ou, mais especificamente, a psicologia e a filosofia da mente. Mas isso inclui também as ciências humanas em geral, já que, segundo Lewes, "para entendermos a Mente Humana, devemos estudá-la sob suas condições normais, e essas são condições sociais" (Lewes 1875a, p.118). Essa concepção, que é enfatizada diversas vezes nas obras do autor, toma a própria ciência da mente como fundamentalmente uma psicologia social, antecipando discussões que só vão surgir nas primeiras décadas do século XX e que existem até hoje com grande controvérsia. ${ }^{6}$

O realismo fundamentado (reasoned realism) de Lewes, que envolve essa forma de perspectivismo, é explicado por ele mesmo de maneira sintética nas seguintes palavras:

A doutrina desta obra, então, pode ser denominada Realismo Fundamentado [Reasoned Realism]. Ela se distingue do Realismo Natural, do Realismo Hipotético e do Realismo Simbólico ou Transfigurado dos pensadores modernos, assim como do realismo convicto das mentes não reflexivas. Ela é uma 
doutrina que procura corrigir a ilusão natural da Razão quando ela tenta corrigir a suposta ilusão dos Sentidos. Eu a denomino Realismo porque ela afirma a realidade daquilo que é dado na Sensação [Feeling]; e Realismo Fundamentado porque ela justifica essa afirmação através de uma investigação das bases e processos da Filosofia, quando a Filosofia explica os fatos dados na Sensação. (Lewes 1875a, p.162s.)

Esse realismo que, como vimos, é também uma forma de perspectivismo, envolve ainda a tese da identidade entre causas e efeitos, o que é de especial interesse para nossa discussão sobre a concepção de lei científica. De fato, a nosso ver, ao defender a identidade entre causas e efeitos, Lewes defende o mesmo ponto que, no caso dos emergentes, preferimos expressar da seguinte maneira: as condições de base de um emergente não são suas causas; elas são apenas suas condições de base, sendo simultâneas com o emergente. De qualquer forma, a noção de poder causal é eliminada. ${ }^{7}$

A distinção proposta por Lewes entre resultantes e emergentes é necessária para compreendermos adequadamente o que está em questão. A confusão entre ambas essas coisas resulta, segundo Lewes, da confusão frequente entre partes componentes e elementos constituintes de alguma realidade. Por exemplo, no nível macroscópico, a metade do conteúdo de um copo d'água possui as mesmas propriedades da totalidade, mas, no nível microscópico, os átomos de hidrogênio e oxigênio não possuem as mesmas propriedades da molécula de água. No primeiro caso, temos uma parte componente, no segundo, os elementos constituintes. Lewes então comenta o seguinte:

A distinção aqui indicada entre Componentes e Constituintes, ou entre Partes e Elementos, se mostrará doravante de importância. Todas as relações quantitativas são componenciais; todas as relações qualitativas, elementais. As combinações entre as primeiras produzem [issue] Resultantes, que podem ser analiticamente mostrados; as combinações das outras produzem Emergentes, que não podem ser vistos nos elementos, nem deles deduzidos. (Lewes 1875a, p.90.)

Aqui já aparece o caráter heteropático, como diz Mill, do caso dos emergentes. Mas antes de passarmos a esse aspecto das leis propriamente, vamos caracterizar um pouco mais precisamente os emergentes. Em outra parte Lewes diz o seguinte:

Assim, embora cada efeito seja o resultante de seus componentes, o produto de seus fatores, não podemos sempre reconstituir os passos do processo de modo a vermos no produto o modo de operação de cada fator. Nesse caso proponho chamar o efeito de emergente. Ele surge das agências combinadas, mas em uma forma que não mostra os agentes em ação. (Lewes 1975b, p.368.)

E logo adiante, na mesma obra, ele diz: 
Além do mais, todo resultante pode claramente ser detectado em seus componentes, porque esses são homogêneos e comensuráveis.

66. É diferente com os emergentes, caso em que, em vez de adicionar um movimento mensurável a outro, ou coisas de um tipo a outros indivíduos de seu tipo, há uma cooperação de coisas de tipos diferentes. [...] O emergente é distinto de seus componentes na medida em que esses são incomensuráveis, e ele não pode ser reduzido seja à sua soma, seja à sua diferença. Mas, por outro lado, ele é como seus componentes ou, falando de forma mais estrita, ele [o emergente] são esses [componentes]: nada pode ser mais parecido com a coalescência dos componentes do que sua coalescência. Diferente como é a água do oxigênio e do hidrogênio separadamente, ou de ambos quando eles não estão combinados, nada pode ser mais parecido com a água do que sua combinação, que é água. (Lewes 1975b, p.369.)

A dificuldade que há no entendimento do caráter ontológico singular dos emergentes em face de suas condições de base aumenta se conservarmos os termos causalistas para explicar isso, como já argumentamos em outra parte (Dutra 2015). Lewes procurou contornar o problema apresentando sua peculiar concepção da causação, identificando causas e efeitos. Foi uma estratégia equivalente àquela de Kant ao introduzir a categoria de comunidade que ele também procurou explicar utilizando termos causalistas, como mostramos no artigo acima indicado.

Em primeiro lugar, Lewes segue a ideia de Comte de substituir as causas pelas leis, como já comentamos. ${ }^{8}$ Para isso ele propõe uma concepção minimalista das causas, isto é, uma concepção funcional, no sentido matemático de função, de forma a eliminar a ideia de poder. As causas são então, para ele, as abstrações que elaboramos para representar as dependências e conexões entre os fenômenos (Lewes 1975a, p.328). Isso envolve também uma concepção ontológica alternativa, que é bem representativa do perspectivismo do autor. Ele afirma que uma "coisa é aquilo que [dela] aparece. Ela é a expressão de uma história particular de eventos, o grupo das condições que se supõe que a determinam" (p.331). Uma coisa é, para utilizar um termo que o próprio autor aí emprega, um complexo, isto é, o complexo de suas relações, especialmente, é claro, aquelas relações com seu observador humano, que a representa em um conceito. Ou, dito de outra forma também adotada pelo autor, um objeto é sua "história corporificada — sendo ele simplesmente o grupo de [suas] Relações" (p.335).

Daí decorre, portanto, a inutilidade para Lewes da noção kantiana de coisa-emsi, como algo que existe mas não nos é dado. Se há, assim, certo perspectivismo na própria posição de Kant, Lewes vai às últimas consequências do perspectivismo, o que quer dizer permanecer no realismo e, assim como Kant, rejeitar toda forma de idealismo metafísico.

Segundo Lewes, quando deixamos de procurar pelos porquês das coisas e nos 
restringimos a procurar saber como elas se nos apresentam, deixamos de lado a ideia de poder que o cientista da natureza usualmente conserva. Comentando ainda o exemplo da composição da água, Lewes diz:

Para além das condições sensíveis, que o físico atribui [a algo], ele acredita que há Algo indefinível, que ele denomina Poder, que faz com que o oxigênio se una com o hidrogênio - algo que dá a tais condições sua eficácia. (Lewes 1975a, p.333.)

É ao criticar a concepção que desde Hume e Kant se tornou padrão - isto é, de que causa e efeito são dois eventos que se sucedem no tempo, sendo que dado o primeiro (a causa) segue-se o segundo (o efeito) - , que Lewes apresenta suas ideias mais originais - e, devemos então dizer, desafiadoras - sobre a causalidade. Ele comenta que, obviamente, procuramos por uma causa onde há mudança, do que decorre a ideia comum de que toda mudança possui uma causa, o que leva também, diz Lewes (1975b, p.335), a tomarmos o termo "causa" significando às vezes a ação observada, às vezes um antecedente da ação. Mas a mera antecedência, diz o autor, não basta para contemplar a noção comum, ao contrário do que propõe Hume, por exemplo, nem mesmo a antecedência invariável, a menos que tal invariabilidade signifique consecução [procession], ou seja:

o antecedente deve entrar no consequente e ficar incorporado nele, caso contrário não o chamaríamos de uma causa. Logo, toda causa é eficiente e passa ao efeito: o processo e o produto são um, vistos sob dois aspectos. (Lewes 1975b, p.336.)

Ou, como ele diz adiante na mesma obra, ao afirmar que a noção de poder é supérflua:

O Poder, então, é nossa expressão abstrata da ação dos agentes. A Causação é essa ação, e não é nada mais. [... $\mathrm{O}$ efeito, produto, é para a causa, processo, o que o ato é para a ação, e a ação para os agentes.

Uma vez reconhecida a identidade da causa e do efeito sob diferentes aspectos, esses aspectos podem ser interpretados como antecedente e consequente, sem a necessidade de qualquer intermediação misteriosa de um terceiro agente ou ligação que os conecte. (Lewes 1975b, p.342.)

E, de uma maneira bastante enfática e sintética, Lewes diz ainda:

a Causa é a expressão condensada dos fatores de qualquer fenômeno, o Efeito sendo o próprio fato. A Causa é o grupo das condições que passam para o efeito, idealmente distinguíveis do produto, mas não realmente separáveis. Na causa e no efeito não há duas coisas, uma precedendo a outra, mas dois aspectos de um fenômeno sucessivamente visto. O efeito é o effectum, o causatum, a consecução da causa. (Lewes 1975b, p.323s.) 
Por fim, vale citarmos ainda a seguinte passagem:

Finalmente, deixe-me dizer que a procura pelas causas é a procura pelas condições especiais que entram nos efeitos e os compõem, e não a inútil procura por algo mais. Um fenômeno é um processo; sua causação é sua consecução [procession]; e isso pode ser visto analiticamente em suas causas componentes e condições, e sinteticamente no efeito resultante. (Lewes 1975b, p.376.)

Acreditamos que esses comentários e citações do autor são suficientes para deixar clara sua doutrina sobre causas, leis e poderes. Em resumo, para Lewes, as leis descrevem processos e um processo, tomado de maneira analítica - isto é, quanto a seus elementos constituintes e forma de ação, seu desenrolar no mundo - , pode ser descrito como uma classe de fatores, as causas, e tomado de maneira sintética, enquanto produto ou resultado do processo, como um efeito. As leis são fórmulas que descrevem abstratamente a história de uma realidade, já que um objeto é sua história corporificada, como vimos. Assim, a lei expressa a forma na qual esse processo decorre, numa função matemática, isto é, em termos mais atuais, apontando as relações funcionais entre determinadas variáveis. Na última seção voltaremos a esse tópico. Por ora, devemos enfatizar que, excluindo a noção de poder, para Lewes, as leis científicas são causais unicamente no sentido acima comentado. Sendo abstrações, como também vimos, de fato, para Lewes, as leis descrevem o comportamento de sistemas ou processos ideais, isto é, de modelos abstratos, tal como descrevemos essa noção em outra parte (Dutra 2013b). E também a esse tópico voltaremos adiante.

\section{John Stuart Mill e as leis heteropáticas}

Embora Lewes tenha proposto a distinção entre emergentes e resultantes, como vimos, e embora ele seja juntamente com Mill um precursor do emergentismo britânico, cujos principais expoentes virão a ser C. Lloyd Morgan e Samuel Alexander, ${ }^{9}$ Lewes não apresenta comentários mais extensos e detalhados sobre as questões relativas à emergência. E nem Mill, de fato, o faz. Esse último, como dissemos, introduz a noção de lei heteropática, que também é fundamental para entendermos as relações entre um emergente e suas condições de base e em que sentido tais relações são nomológicas ou legiformes, isto é, se dão segundo determinadas leis. Como vamos discutir na última seção, tais relações não são causais a não ser no sentido especial em que Lewes toma o termo "causa", como vimos na seção anterior.

Mill não se dá conta disso, mas, ao contrário de Lewes - cuja concepção da causalidade, que vimos acima, é uma exceção na tradição filosófica - Mill sustenta a mesma concepção comum segundo a qual a causa é o evento antecedente no tempo numa conjunção invariável (Mill 1882, p.236s e p.245). Sua discussão sobre as leis heteropáticas ocorre no contexto daquela sobre a composição de causas, o que para 
ele envolve a composição de leis. Sem poder lidar adequadamente com o caso da simultaneidade, que pode ser encarado do ponto de vista causalista como um caso de composição, contudo, Mill considera o caso em que a causa não cessa quando o efeito tem lugar e, em relação com isso, o caso da simultaneidade entre causa e efeito. Ele diz o seguinte:

Uma causa sempre está com respeito a seu efeito numa relação de antecedente e consequente? Não dizemos frequentemente de dois fatos simultâneos que eles são causa e efeito - como quando dizemos que o fogo é a causa do calor, o sol e a umidade a causa da vegetação e outras coisas assim? Uma vez que a causa não desaparece necessariamente porque seu efeito foi produzido, as duas coisas realmente coexistem geralmente, e há algumas aparências e algumas expressões comuns que parecem implicar não apenas que as causas podem ser contemporâneas com seus efeitos, mas que elas devem ser. Cessante causa cessat et effectus, esse tem sido um dogma das escolas; a necessidade da existência continuada da causa para a continuidade do efeito parece ter sido alguma vez uma doutrina amplamente aceita. [...]

Há, portanto, uma distinção a ser feita. As condições que são necessárias para a primeira produção de um fenômeno, ocasionalmente, são também necessárias para sua continuidade, embora seja mais comum que sua continuidade não requeira mais que as condições negativas. (Mill 1882, pp.247-8.)

Por "condições negativas" Mill entende aquelas condições que poderiam ser fatores inibidores das condições positivas, isto é, aquelas que são as estimuladoras de um acontecimento. De fato, na definição mais elaborada que ele apresenta da causalidade (Mill 1882, p.241), é assim que ele se expressa. De maneira completa, a causa de um fenômeno, segundo o autor, é a classe de todas as condições positivas e negativas. Ou seja, um fato qualquer tem lugar quando estão postas as condições positivas para que ele exista, excluídas as condições negativas. Isso envolve, obviamente, poderes e propriedades, como o próprio Mill reconhece (1882, p.249).

Consideremos agora o caso da simultaneidade entre a causa e o efeito. Mill não entende que tal possibilidade - que, ele reconhece, é uma realidade frequente seja base de argumento contra sua definição de causa, pois, de qualquer forma, para ele, seja a causa algo antecedente, seja algo concomitante com o efeito, são certos poderes e certas leis que entram em cena para que determinados acontecimentos se deem. Ele comenta:

Há certamente casos nos quais o efeito se segue sem qualquer intervalo perceptível para nossas faculdades; e quando há um intervalo, não podemos dizer por meio de que ligações intermediárias imperceptíveis para nós esse intervalo pode realmente ser preenchido. Mas mesmo admitindo que um efeito possa começar simultaneamente com sua causa, a concepção da causação que aceito não é afetada nem um pouco. Se a causa e o seu efeito são 
necessariamente sucessivos ou não, o começo de um fenômeno é o que implica a causa, e a causação é a lei de sucessão dos fenômenos. (Mill 1882, p.248.)

Contudo, isso não resolve de forma alguma os casos de simultaneidade genuína, ou absoluta, se quisermos dizer assim, isto é, aqueles casos em que não é possível discriminar entre dois eventos aquele que seria a causa porque não temos como observar o começo dos acontecimentos. O exemplo dado por Mill da suposta simultaneidade entre o fogo e o calor é inadequado. Se sentimos o calor diante do fogo de uma lareira, podemos tomar esse último como causa do calor porque a experiência, primeiro, mostra que não havia calor antes de acendermos o fogo e, segundo, mostra também que se apagarmos o fogo, o calor vai cessar. Quando claramente a experiência exibe a antecedência de um dos eventos, como afirma Kant em sua discussão da causalidade, utilizamos a categoria de causação. Mas num caso genuíno de simultaneidade, como ao observarmos os movimentos relativos um ao outro da terra e da lua, não podemos empregar a mesma categoria, e sim aquela de comunidade, diz Kant. ${ }^{10}$ Tal como vamos comentar adiante, esse caso genuíno de simultaneidade é que há entre as condições de base de um emergente e esse último.

Antes disso, tomemos o caso da noção de lei defendida por Mill. Ele também sustenta que o estudo da natureza é o estudo de leis (Mill 1882, p.231). Ele reconhece que não deixa de ser pertinente a noção comum segundo a qual onde há uma regularidade, há uma lei. Contudo, para ele, uma lei da natureza é a expressão de uma regularidade mais fundamental. Ele diz:

O primeiro ponto, portanto, a ser notado com respeito àquilo que é chamado de uniformidade do curso da natureza é que, em si mesmo, isso é um fato complexo, composto de todas as uniformidades separadas que existem com relação aos fenômenos simples. Essas diversas uniformidades, quando afirmadas pelo que é encarado como uma indução suficiente, na linguagem comum, chamamos de Leis da Natureza. Cientificamente falando, esse título é empregado em um sentido mais restrito, para designar as uniformidades quando reduzidas à sua expressão mais simples. (Mill 1882, p.229.)

O exemplo dado por ele a esse respeito é o da regularidade observada da coluna de mercúrio num tubo de Torricelli. Essa regularidade, que é um dos inúmeros casos complexos, não é uma lei da natureza, mas ocorre em virtude daquelas regularidades que são genuínas leis da natureza - um ponto com o qual se pode perfeitamente estar de acordo com Mill, é claro. Contudo, as leis heteropáticas, segundo ele, surgem em contextos de grande complexidade. Aqui reside a ideia emergentista seminal de Mill, pois certos contextos de complexidade dão lugar a novas leis da natureza. Trata-se, segundo ele, de um caso de composição de causas, mas de um caso todo especial. Ele introduz essa noção da seguinte maneira: 
Quando, em resumo, uma concorrência de causas acontece, pondo em ação novas leis que não têm analogia com qualquer uma que possamos discernir na operação das causas, as novas leis, mesmo que elas se sobreponham a uma parte das leis anteriores, podem coexistir com outra parte, e podem mesmo de sua parte compor o efeito daquelas leis anteriores.

Mais uma vez, essas próprias leis, que são geradas dessa segunda maneira, podem produzir outras, da primeira maneira. Embora haja leis, como aquelas da química e da fisiologia, que devem sua existência a uma quebra do princípio de Composição das Causas, não se segue que essas leis peculiares ou, como elas podem ser chamadas, leis heteropáticas, não sejam capazes de composição umas com as outras. [...] pois, embora seja impossível deduzir todas as verdades químicas e fisiológicas das leis ou propriedades das substâncias simples ou agentes elementares, possivelmente, elas podem ser deduzidas das leis que começam quando esses agentes elementares são associados em algum número moderado de combinações não muito complexas. As leis da vida nunca serão dedutíveis das meras leis dos ingredientes, mas os Fatos prodigiosamente complexos da Vida podem ser todos dedutíveis de leis comparativamente simples da vida; leis que (dependendo, de fato, de combinações, mas de combinações comparativamente simples, de antecedentes) podem em circunstâncias mais complexas se comporem estritamente umas com as outras e com as leis físicas e químicas dos ingredientes. Os detalhes dos fenômenos vitais, mesmo agora, permitem inúmeras exemplificações da Composição das Causas; e à medida que esses fenômenos são mais estudados, parece haver mais razão para acreditar que as mesmas leis que operam nas combinações mais simples de circunstâncias, de fato, continuem a ser observadas naqueles mais complexos. Isso vai se verificar igualmente verdadeiro nos fenômenos da mente; e mesmo nos fenômenos sociais e políticos, que resultam das leis da mente. (Mill 1882, p.269.)

Não é de espantar que essa passagem seja um locus classicus do emergentismo. As principais ideias estão aí colocadas e, surpreendentemente, exibem o caráter de simultaneidade que o próprio autor não percebeu. Pois a emergência das leis heteropáticas nos contextos de complexidade - como nos fenômenos vitais e mentais - não suprime a ação das leis mais simples, isto é, das leis relativas às condições de base do fenômeno emergente. Logo após a passagem acima citada, Mill comenta que mesmo no caso da química há leis heteropáticas. Ou seja, os compostos químicos já são casos de emergentes, e não de resultantes, para empregarmos os termos de Lewes, ainda que Mill seja otimista o suficiente para achar que o progresso da ciência poderá permitir descobertas que tornem o estudo desses fenômenos mais complexos também dedutivo, isto é, que a partir de certas condições iniciais, dado o conhecimento das leis, possamos deduzir os fenômenos emergentes (Mill 1882, p.270s). Nesse caso, estritamente falando, nos termos de Lewes, o antigo emergente deverá passar a ser considerado um resultante. 
Essa conclusão, que poderia parecer algo contraintuitivo do ponto de vista emergentista, de fato, não é, e isso tem a ver com o caráter perspectivista do emergentismo, como vamos procurar explicar na próxima seção. Numa ontologia de processos que são o que são - processos - apenas na medida em que envolvem o observador, isto é, nós mesmos, não há categorias ontológicas perenes, substâncias, para usarmos o termo da metafísica tradicional. Mas então a questão que se põe é em que medida esse emergentismo perspectivista ainda pode sustentar uma concepção de leis da natureza ou, se preferirmos a formulação mais contemporânea, leis científicas. É o que veremos em seguida.

\section{As leis científicas segundo o emergentismo perspectivista}

A nosso ver, o perspectivismo é inerente ao emergentismo e dele indissociável. Pois considerar, de um lado, os elementos constituintes das condições de base de um emergente ou, de outro, esse último como uma totalidade funcional, isso é uma questão de ponto de vista. Nem por isso é arbitrário ou meramente subjetivo.

O emergentismo é uma ontologia da complexidade, mais especificamente, da complexidade evolutiva, como um de seus autores mais representativos deixa claro em sua obra mais conhecida: Lloyd Morgan (1927). Sua ideia mais fundamental é que a partir de processos mais simples (aqueles que, segundo as ciências e a filosofia atuais, seriam os processos físicos) surgem novos sistemas - sistemas esses cujo comportamento não pode ser inferido do conhecimento de seus elementos constituintes, sistemas mais complexos, portanto. E, numa ordem crescente de complexidade, tal como podemos observar em nosso planeta, emergem sistemas de complexidade cada vez maior, como aqueles que classificamos como químicos, vitais, mentais e sociais, para nos atermos às categorias usuais.

Essa ontologia, como sabemos, é também materialista e se distingue de outras formas de materialismo - aquelas que seriam reducionistas - por afirmar que, embora não haja quaisquer princípios (ou poderes, capacidades fundamentais) não físicos, as realidades ou sistemas emergentes adquirem propriedades emergentes, isto é, propriedades que não se encontram nos elementos das condições de base dos emergentes. Essa forma de materialismo não reducionista sustenta que tudo no mundo é feito de matéria e energia, para tomarmos uma forma mais tradicional de dizer, ou de quaisquer realidades últimas que as ciências físicas estudam. Mas sustenta ao mesmo tempo que determinadas propriedades das coisas que, em última instância, são todas materiais, são propriedades emergentes e irredutíveis a propriedades da matéria bruta.

Além disso, o emergentismo é evolutivo de uma forma não teleológica, nem teológica, portanto. As realidades emergentes não estão em nenhum plano preconcebido, nem se direcionam a um fim pré-determinado. Nesse sentido, o emergentismo é uma 
ontologia aberta, isto é, uma forma de encarar a estrutura fundamental da realidade de um modo não direcionado, o que inclui o acaso, no sentido de que certas realidades emergem em virtude da interação ocasional de realidades dadas anteriormente. Por isso a evolução emergente não se dá segundo uma lei; nesse sentido realista e teleológico não há, para o emergentista, leis da natureza. Mas o fato de que haja propriedades emergentes implica que haja leis que, a partir de determinado momento, serão exibidas em processos cujo comportamento não é compreensível apenas com base no comportamento - e leis a ele relativas - dos elementos constituintes de suas condições de base. Esse é o caráter heteropático, para utilizarmos o termo de Mill, de todas as leis emergentes.

A expressão "condições de base", tal como já comentamos, indica todos os fatores (coisas, ou sistemas, ou realidades) que, uma vez postos, dão ocasião à emergência de uma realidade nova. Para repetirmos o exemplo mais simples que sempre encontramos nos textos dos emergentistas, hidrogênio e oxigênio são parte das condições de base da água. Mas essas condições de base não podem ser a causa da água como efeito emergente - expressão essa que seria, a rigor, para o emergentista, uma contradição, já que um emergente não é um efeito, um resultante; ele é um emergente justamente, tal como Lewes define esses termos. As condições de base de um emergente não são sua causa porque não possuem as mesmas propriedades do emergente. Pois a relação causal, tal como vimos acima, pelo menos na interpretação mais tradicional, inclusive aquela de Mill, envolve a noção do poder que a causa tem de produzir o efeito. E tal poder seriam já as propriedades emergentes do emergente antes de ele surgir. Contudo, segundo a interpretação da causalidade de Lewes, que também vimos acima, ainda poderíamos utilizar os termos causalistas, mas ficaria excluída qualquer atribuição de poder ou capacidade ao conjunto das condições de base de um emergente. Todas as condições de base da água: hidrogênio, oxigênio etc., para ficarmos no mesmo exemplo, não são água - porque não têm as propriedades da água. Mas, de uma forma analítica (ou talvez utilizando termos aristotélicos, diríamos: potencial), quando identificamos as condições de base da água, podemos dizer que ali já está a água, pois não há água onde não há hidrogênio, oxigênio etc.

Passemos a um exemplo mais interessante - e desafiador para o pensamento contemporâneo: determinados processos neurofisiológicos em nossos cérebros são as condições de base de um estado mental nosso, pois não há nenhum evento ou estado mental nosso que se dê sem tais processos neurofisiológicos; mas o evento ou estado mental tem propriedades que essas suas condições de base não têm. Portanto, no sentido causalista tradicional, que envolve a ideia do poder da causa de produzir o efeito, os processos neurofisiológicos do cérebro não são a causa dos eventos mentais. A noção correta é a de que tais processos neurofisiológicos são as condições de base dos eventos mentais, que são emergentes. Retomando um dos pontos que discutimos antes, a simultaneidade entre os processos neurofisiológicos e o evento 
mental impede o uso da noção de causação, no sentido kantiano, mas sugere o uso daquela de comunidade, da existência concomitante entre o emergente mental e suas condições de base neurofisiológicas.

Aqui vale comentarmos que, ao contrário do que pensava Davidson, que sustentava o caráter anômalo ou, mais propriamente dizendo, não nomológico, do mental em relação ao neurofisiológico, o emergentista afirma apenas o caráter heteropático das regularidades mentais em relação àquelas dos processos neurofisiológicos. Isso quer dizer que, em relação às leis neurofisiológicas que descrevem o comportamento do cérebro humano, possíveis leis mentais ou psicológicas guardariam a mesma relação cujo caráter é heteropático, isto é, tais leis psicológicas seriam leis heteropáticas, como, aliás, o próprio Mill comenta, como vimos na seção precedente. Mas, por que o emergentista falaria da possibilidade de tais leis psicológicas, e não de sua realidade. Por causa do caráter essencialmente perspectivista do emergentismo, tal como Lewes deixa bem claro ao falar das leis, como vimos. É nossa capacidade de descobrir e formular as leis que conta. Não podemos presumir que a realidade não dada (a realidade em si, kantianamente falando) já possua leis.

Para o realismo ingênuo (que também não é o realismo kantiano, como sabemos, pois Kant localizava as leis no entendimento humano e não nas coisas), as leis estão nas coisas. Para o emergentista, como vimos com Lewes, elas estão em nossa forma de representar nossas interações com as coisas. Somos nós que representamos certas partes da realidade como uma relação entre certas condições de base e um emergente. Isso quer dizer que é para nós que há, por exemplo, água onde há hidrogênio, oxigênio e certos fatores ambientais. É para nós que há neles algum poder de fazer surgir água. Embora, tomando esse exemplo, para o realismo ingênuo, o que acabamos de dizer possa soar como uma afirmação absurda, consideremos um exemplo que tem sido mais feliz para esclarecer esse ponto, a saber, aquele das cores que vemos. ${ }^{11}$

Como sabemos bem hoje, as cores que vemos (nós que pertencemos à maioria da população humana neste planeta, que é formada dos chamados tricromatas, os que possuem em suas retinas três tipos de células cone) dependem de três ordens de fatores: além das já mencionadas células cone de nossa retina, das propriedades da luz que incide em nossa atmosfera, as cores que vemos dependem, por fim, das propriedades das superfícies que refletem tal luz. Portanto, temos aí as condições de base da visão das cores que vemos como um processo emergente. A visão das cores por um de nós é um processo mental que tem como condições de base aquelas ordens de fatores físicos e fisiológicos. Isso quer dizer que tais cores que vemos são reais, pois as vemos onde e quando quer que tais condições de base estão postas. Mas elas são reais para nós. As coisas não são coloridas a não ser para nós. É o realismo perspectivista que permite compreender isso, que é incompreensível para o realismo ingênuo. 
Um último ponto deve ser considerado mesmo que, junto com o emergentista, aceitemos a ideia de que as propriedades emergentes de certas realidades não estão em suas condições de base. Já que a evolução emergente começa em processos que não podemos observar nem representar, como poderíamos eliminar completamente a noção de poder ou de certas propriedades fundamentais da matéria que seriam, afinal, responsáveis pelo menos pelos processos mais básicos da realidade física? Suponhamos juntamente com uma parte (controvertida) da física atual que a realidade última seja aquela das cordas (strings). Desse ponto de vista, não só não cabe falar da matéria, como tradicionalmente se fez, mas nem mesmo das partículas fundamentais de que a mecânica quântica trata. Uma ideia comum às teorias das cordas é que os quarks resultam de diferentes frequências nas quais vibram as cordas. ${ }^{12}$ Essas realidades fundamentais do mundo postuladas pela teoria, ainda que conceitualmente bem elaboradas, não nos são dadas e não satisfazem todas as condições empíricas para que possamos considerá-las devidamente representadas por nós, como reconhecem os próprios defensores da teoria.

Poderíamos tentar resolver essa questão por meio de uma discussão epistemológica mais técnica na qual, por exemplo, seguindo Kant, poderíamos dizer que as cordas podem ser pensadas mas não conhecidas. Ou então, seguindo Lewes, como vimos acima, poderíamos negar a distinção entre fenômeno e coisa-em-si e dizer que as cordas satisfazem os critérios por esse autor elaborados para que sejam para nós fenômeno. Acreditamos que nenhum desses dois autores nos convencerá com seus critérios epistemológicos sutis, de forma a eliminar todas as dúvidas e objeções. A nosso ver, por mais que consideremos em geral todas as propriedades das coisas como relacionais e, logo, sempre cognoscíveis nas relações das coisas entre si (por exemplo, na relação conosco, certas coisas são coloridas, como vimos), não é possível eliminar completamente da ciência a noção de propriedade não relacional, ou seja, daquilo que tradicionalmente se tem denominado os poderes das coisas.

Por exemplo, Locke, que também tem uma postura claramente perspectivista, como sabemos, por afirmar que o que conhecemos são nossas ideias, ao comentar sobre os dois limites do conhecimento humano, a saber, das coisas muito distantes de nós e daquelas muito diminutas, diz a respeito desse segundo limite:

Mas uma vez que somos destituídos de sentidos aguçados o suficiente para descobrir as partículas diminutas dos corpos, e nos oferecermos ideias de suas afecções mecânicas, devemos nos conformar em sermos ignorantes de suas propriedades e modos de operação; nem podemos estar seguros sobre elas para além do que podem atingir algumas poucas tentativas que fazemos. Mas se elas vão ser bem sucedidas mais uma vez em outra ocasião, disso não podemos estar certos. Isso limita nosso conhecimento certo das verdades universais a respeito dos corpos naturais, e nossa razão nos conduz nesse domínio muito pouco para além de questões de fato particulares. (Locke 1996[1690], L. IV, cap. III, §25.) 
E em outra de suas famosas passagens, ao comentar a ideia de poder especificamente, Locke diz:

Sendo a mente todo dia informada pelos sentidos da alteração daquelas ideias simples que ela observa nas coisas externas, e notando como uma termina e deixa de existir, e outra, que não havia antes, começa a existir, refletindo também sobre o que se passa dentro de si mesma e observando uma mudança constante em suas ideias, às vezes pela impressão dos objetos externos sobre os sentidos e às vezes pela determinação de sua própria escolha, e concluindo daquilo que ela tão constantemente observou que aconteceu que as mesmas mudanças vão no futuro ser feitas nas coisas pelos mesmos agentes e das mesmas maneiras, considera em uma coisa a possibilidade de ter qualquer de suas ideias simples modificada e na outra a possibilidade de produzir essa mudança, chegando, assim, à ideia que denominamos poder. Desse modo, dizemos que o fogo tem o poder de derreter o ouro, isto é, de destruir a consistência de suas partes insensíveis e, consequentemente, sua rigidez, tornando-o fluido, e que o ouro tem o poder de ser derretido, que o sol tem o poder de branquear a cera, e a cera tem o poder de ser branqueada pelo sol, por meio do que sua cor amarela é destruída, e o branco passa a existir em seu lugar. Em casos como esses, o poder que consideramos é em referência à mudança de ideias perceptíveis. Pois não podemos observar qualquer alteração a ser feita em qualquer coisa ou operação sobre ela a não ser pela mudança observável em suas ideias sensíveis. .. (Locke 1996[1690], L. II, cap. XXI, §1, itálico no original.)

Em outras palavras, por um lado, atribuímos poderes a determinadas coisas, para explicarmos suas relações, poderes ocultos que podemos eliminar à medida que avança o conhecimento da natureza, mas que, por outro lado, não podemos eliminar total e absolutamente. Para os recursos analíticos de determinado tempo, certas propriedades podem ser reduzidas a outras, mais fundamentais, e mesmo determinadas entidades podem ser reduzidas a outras relações, entre entidades mais fundamentais.

Outro autor do século XIX (aliás, diversas vezes citado por Lewes), Claude Bernard, expressou isso de uma forma bem sintética, dizendo que o progresso da ciência pode reduzir propriedades a fenômenos, ou seja, mostrar que determinada coisa que exibe alguma propriedade pode ser depois descrita como uma relação entre outras coisas, devido às propriedades dessas outras coisas. Bernard dizia que, em seu tempo, na fisiologia, a única propriedade não eliminável dessa forma era a irritabilidade do protoplasma celular. Mas, para ele, era possível que a fisiologia do futuro viesse a reduzir tal propriedade a certos fenômenos (Bernard 1966, p.280s, esp. p.288). No caso da matéria bruta, os progressos da microfísica no século seguinte fizeram isso em larga medida. E, curiosamente, de fato, Bernard comenta:

Mas se quisermos descer ainda mais profundamente na análise dos fenômenos que examinamos, veremos que, na verdade, a irritabilidade, tal como a sensibilidade ou as sensibilidades, que todas as propriedades vitais, tanto 
quanto todas as funções, são criações de nossa mente, representações metafísicas sobre as quais não podemos, por conseguinte, fazer chegar nossa ação. (Bernard 1966, p.290.)

Há aí, portanto, certo perspectivismo também, algo que muito poucos contemporâneos de Bernard (Lewes foi uma exceção) puderam entender em seu pensamento, sempre tomando-o como um defensor ou de um materialismo redutivista, ou de um idealismo absoluto, como uma passagem como essa acima poderia sugerir. O perspectivismo, do qual nem o próprio Bernard se deu conta claramente e, portanto, sem ter as formas adequadas de expressão de seu pensamento, permite mostrar que se trata de um tipo peculiar de realismo, um realismo sofisticado que concilia o caráter abstrato das realizações científicas com a pesquisa experimental, com um mundo de positividade do qual não podemos fugir, como insistem Locke, Mill, Lewes e o próprio Bernard.

A ontologia defendida pelo emergentismo perspectivista está de acordo também com essas ideias de Locke e Bernard. Ela é uma ontologia aberta também no sentido regressivo, digamos, e não apenas no sentido progressivo da emergência de novas realidades. Sendo uma ontologia de processos, não há para ela entidades fundamentais a não ser, pragmaticamente, dadas as capacidades analíticas da ciência em determinado tempo. E aí, pelo menos pro tempore, vai restar a ideia de poder.

\section{Considerações finais}

O realismo perspectivista e emergentista - ou realismo fundamentado (reasoned), como diz Lewes - mantém as noções de lei científica, de causas (naturais e sociais) e de propriedades (ou poderes, ou capacidades), sejam elas últimas em relação a nossas capacidades analíticas em algum momento do desenvolvimento das ciências, sejam elas emergentes.

As leis são nossas expressões funcionais, no sentido matemático, das correlações entre os acontecimentos; elas são, como vimos, fórmulas abstratas de processos que podem ser entendidos como os sucessivos estados de um sistema; elas são a expressão sintética de seu modo típico de comportamento.

As leis heteropáticas, como diz Mill, entram em cena quando representamos para a mesma região do mundo, o mesmo locus, duas ou mais diferentes ordens de processos. Por exemplo, num ser humano, há processos físicos, neurofisiológicos e mentais que se dão ao mesmo tempo, que são condições de base uns dos outros, sistemas simultâneos e interdependentes. Os processos físicos (possivelmente quânticos) que ocorrem em nossos neurônios são (parte das) condições de base dos eventos neurofisiológicos que, por sua vez, são (parte das) condições de base dos eventos mentais em nós. Mas tais processos físicos e neurofisiológicos não são causas dos processos 
mentais, assim como, se focalizarmos apenas a relação entre os processos físicos e neurofisiológicos, os primeiros não são causas dos segundos. Como vimos acima, são apenas suas condições de base. As condições de base de um sistema ou processo são simultâneas com ele, e por isso não podem ser tomadas como sua causa, se entendermos pelo termo a relação de sucessão entre acontecimentos que estão certamente relacionados.

Nesse caso, temos o que Lewes chamou de resultantes. A relação entre os antecedentes de um resultante e esse último, de fato, pode ser descrita de maneira causal. Isso significa que, onde e quando quer que determinadas condições iniciais se colocam (os fatores antecedentes), determinados outros acontecimentos têm lugar (o resultante). Mas nem nesse caso, nem naquele da relação entre as condições de base de um emergente e esse último, ainda que possamos descrever de forma nomológica certas propriedades das coisas, não temos os poderes no sentido causalista tradicional, isto é, como a capacidade da causa de produzir o efeito.

Contudo, mesmo assimilando a noção tradicional de poder àquela de propriedades (relacionais ou mesmo últimas), não temos como eliminar completamente aquelas que seriam as propriedades fundamentais das coisas, pois isso depende de nossa capacidade de análise e representação dos processos que constituem a realidade. Nesse sentido, a noção de poder é uma espécie de resíduo ontológico. E esse resíduo é relativo à nossa perspectiva, sempre, ainda que ela possa mudar com o desenvolvimento das ciências.

\section{Referências}

Bernard, C. 1966[1878]. Leçons sur les phénomènes de la vie communs aux animaux et aux végétaux. Paris: Vrin.

Cartwright, N. 1989. Nature's Capacities and Their Measurements. Oxford: Clarendon Press.

Davidson, D. 1980. Essays on Actions and Events. Oxford: Oxford University Press.

Dutra, L. H. de A. 2013a. Emergência e realismo perspectivista. Scienciae Studia 11(3): 63765.

Dutra, L. H. de A. 2013b. Pragmática de modelos. Natureza, estrutura e uso dos modelos científicos. São Paulo: Edições Loyola.

Dutra, L. H. de A. 2015. Emergência sem níveis. Scienciae Studia 13(4): 841-65.

Dutra, L. H. de A. 2018. Autômatos geniais. A mente como sistema emergente e perspectivista. Brasília: Editora UnB.

Giere, R. N. 2006. Scientific Perspectivism. Chicago e Londres: The University of Chicago Press.

Greene, B. 1999. The Elegant Universe. Superstrings, Hidden Dimensions, and the Quest for the Ultimate Theory. Nova York: W. W. Norton.

Lewes, G. H. 1875a. Problems of Life and Mind. First Series: The Foundations of a Creed, vol. I. Boston e Nova York: Houghton, Mifflin \& Co. 
Lewes, G. H. 1875b. Problems of Life and Mind. First Series: The Foundations of a Creed, vol. II. Londres: James R. Osgood \& Co.

Locke, J. 1996[1690]. An Essay concerning Human Understanding. Indianápolis: Hackett.

Mill, J. S. 1882[1843]. A System of Logic, Ratiocinative and Inductive. Nova York: Harper \& Brothers.

Morgan, C. L. 1927[1923]. Emergent Evolution. The Gifford Lectures Delivered in the University of St. Andrews in the Year 1922. Londres: Willliams and Norgate.

Randall, L. 2006. Warped Passages. Unraveling the Mysteries of the Universe's Hidden Dimensions. Nova York: Harper Collins.

\section{Notas}

${ }^{1}$ É claro que para a mecânica clássica, que postula a força da gravidade como uma magnitude natural, não há esse problema, sendo tal força (tal poder) a verdadeira causa da gravitação entre a terra e a lua. Mas, de uma forma pós-newtoniana bem interessante, Lewes argumenta que a gravitação são os próprios movimentos dos corpos em relação. Cf. Lewes 1875a, cap. III, esp. p.49s.

${ }^{2}$ Nosso realismo emergente e perspectivista é tratado extensamente em Dutra 2018, especialmente em relação aos eventos mentais. Cf. também Dutra 2013a e 2015.

${ }^{3} \mathrm{Cf}$. Lewes 1875a, p.335s.

${ }^{4}$ Cf. também Lewes $1875 a$, p.25. As críticas do autor a Kant e à ideia de que há um domínio de coisas-em-si, que pode ser pensado, mas não conhecido, se encontram, por exemplo, no capítulo II da mesma obra, p.12s. Lewes nega a própria distinção kantiana entre fenômeno e coisa-em-si (p.168). Não pode haver coisas-em-si porque todas as coisas nos são dadas. O perspectivismo de Lewes implica, portanto, também a negação da própria distinção de Kant entre pensar e conhecer. O que pode ser pensado é o que pode ser conhecido, porque é também o que pode ser correlacionado com a experiência. Aqui vemos não apenas o caráter empirista, mas positivista, do pensamento de Lewes.

${ }^{5}$ Cf. Também Lewes $1875 a$, p.96, onde o autor diz que é uma falácia pensar que as leis regem os fenômenos, em vez de simplesmente expressá-los em uma fórmula.

${ }^{6}$ Cf. também Lewes $1875 \mathrm{a}, \mathrm{p} .140$ s, onde o autor discute a diferença entre os seres humanos e as outras espécies animais e enfatiza o papel da linguagem na aquisição da consciência reflexiva e da moralidade, sendo a linguagem ao mesmo tampo "causa e efeito da Civilização" (p.144). E é isso, obviamente, o que possibilita todo conhecimento: "A linguagem — que é inteiramente um produto social para uma necessidade social - é o carro chefe da operação simbólica, e o único meio pelo qual a Abstração pode ser realizada" (p.154). Cf. ainda p.159s.

${ }^{7}$ Como procuramos mostrar em Dutra 2015, a pressuposição comum mesmo entre os emergentistas de que as condições de base de um emergente são suas causas é um grande equívoco e só se sustenta se tomarmos os elementos que figuram nas condições de base de um emergente como sua causa material no sentido aristotélico. Por exemplo, dois átomos de hidrogênio e um átomo de oxigênio são elementos das condições de base da molécula de água, mas não fazem parte da causa da molécula de água como um efeito de tal causa, não no sentido do termo "causa" tal como é tomado por Locke, Hume e Kant, isto é, como um evento que precede outro (o efeito) no tempo. Vale lembrarmos que, no caso do exemplo 
acima, os átomos de hidrogênio e oxigênio não são as únicas condições de base para que a molécula de água emerja. Há outras condições de base ambientais, como sabemos, tal como temperatura, pressão etc.

${ }^{8}$ Cf. o cap. X de Lewes 1975a, no qual estão seus principais comentários a esse respeito, p.327s.

${ }^{9}$ Cf. nossas obras já mencionadas: Dutra 2013a, 2015 e 2018, que comentam também as ideias de autores emergentistas atuais.

${ }^{10} \mathrm{Cf}$. Dutra 2015, para uma extensa e detalhada discussão desse tópico. De sua parte, Mill apresenta uma longa discussão no capítulo V ("Da lei da causação universal") do livro III de sua citada obra (Mill 1882) a respeito da força e outras noções empregadas na física, inclusive a gravidade, mas sem tratar adequadamente do caso da simultaneidade genuína.

${ }^{11}$ Ao apresentar seu realismo perspectivista, Ronald Giere (2006) utiliza exatamente este ponto de partida, recapitulando os aspectos fundamentais revelados pelas atuais ciências que tratam do assunto.

${ }^{12}$ Estamos, obviamente, simplificando enormemente o assunto, que é exposto de forma bem compreensível em Greene 1999, e Randall 2006, por exemplo. 